\title{
A study of modified and economical approach to canalicular tear using intravenous cannula in tertiary care centre
}

\author{
Anuradha $\mathrm{A}^{1, *}$, Vinuta Mohan Kulkarni ${ }^{2}$, Vidya Devi $\mathbf{M}^{3}$, Ranjitha $\mathrm{C} \mathrm{S}^{4}$

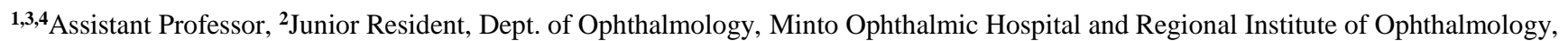 \\ BMCRI, Bangalore, Karnataka, India
}

*Corresponding Author: Anuradha A

Email: anudranu@gmail.com

\begin{abstract}
Purpose: Study aims to demonstrate and evaluate a modified and economical way of repairing canalicular tear using intravenous cannula in tertiary care centre.

Materials and Methods: 32 patients with canalicular tear admitted in Minto Ophthalmic Hospital, regional institute of ophthalmology were taken in the study. Patients were operated for canalicular tear repair using intravenous cannula of $24 \mathrm{G}$ size. Functional and anatomical success of the procedure evaluated during the follow up. Data collected and analysed using descriptive statistics.

Results: Out of 32 patients, 24 were males and 8 females. Right eye was involved in 22 patients and left eye in 10 patients. Various mode of injury includes dog bite, Road Traffic Accidents, assault, self-injuries, domestic violence, cooker blast in varying percentages. Functional and anatomical success was seen in $93.75 \%$ of the patients.

Conclusion: Using intravenous cannula is an economical way of canalicular tear repair with easy availability and no extra cost to the patient. With the least complications, this technique can be adapted in Government set up as this is more economical.
\end{abstract}

Keywords: Canalicular tear, Eye lid injury, Intravenous cannula.

\section{Introduction}

Eye lid lacerations are common secondary to blunt or penetrating trauma of orbit, animal bites especially dog bites and self-fall, road traffic accidents, assaults, self-inflicted injuries etc. Canalicular tear involves the $16 \%$ of the eye lid lacerations ${ }^{1}$ and it is recognised by following codes by World Health Organisation, International Classification of Diseases as ICD 9-CM and ICD 10- CM. Proper and meticulous repair of canalicular tear is important to retain the anatomy and functional integrity of the lacrimal system and prevent of canaliculus scarring leading to epiphora.

Various surgical treatment techniques and materials for intubation have been previously described, such as Crawford (bicanalicular) and Ritleng (bicanalicular) intubation systems and Mini Monoka stents (unicanalicular). Many modifications have been tried in the past and have proved to be successful. Chu et al. found direct canalicular wall suturing has better outcome than pericanalicular tissue suturing. ${ }^{2}$ Kersten and Kulwin demonstrated an easy technique of "one-stitch" canalicular repair with $95.5 \%$ success. ${ }^{3}$ Tint et al. also demonstrated success of $97.3 \%$ of patients using bicanalicular stents. ${ }^{4}$

Present study demonstrates and evaluates the success of a novel and economical way of canalicular tear repair using intravenous cannula of $24 \mathrm{G}$ size which is readily available in the hospitals.

\section{Materials and Methods}

A retrospective study was conducted on patients admitted in Minto Regional Institute of Ophthalmology, Bangalore medical college and research institute, with canalicular tear due to different modalities of injuries. Study was done from December 2012 to January 2018. Detailed history pertaining to trauma taken, eye lid injury evaluated under slit lamp microscopy to look for the canalicular tear and the extent noted. First, general condition of the patient stabilised and given importance to life threatening conditions. First aid care are fulfilled like giving injection TT, and giving broad spectrum antibiotics, cleaning the wound area of all the debris, ruling out other associated injuries and planning the treatment for the same. Canalicular injuries are most often associated with medial eye lid lacerations and globe injuries and orbital wall injuries. Globe injuries are corrected first before treating canalicular tear.

Under aseptic precautions, eye is painted and draped. Generally the punctal end is easily identified under the operating microscope. The nasal or the proximal cut end is difficult to identify. Thereby the identification of the proximal cut end is facilitated by use of Bowmans probe, where in we can see whitish onion ring like rounded structure through operating microscope. Use of phenyl ephrine on the tissues causes constriction of vessels in the surrounding tissues and makes canaliculi identifiable, also use of visco elastic distends the canaliculi. In our study we have used a intravenous cannula with injection port and wings of $24 \mathrm{G}$, which has $0.7 \mathrm{~mm}$ of diameter, $19 \mathrm{~mm}$ of length. (Fig. 1) It is supplied at free of cost to our tertiary care centre, which is under Government of Karnataka. After identification of the cut ends of the canaliculi, the intravenous cannula is inserted into the canaliculi into the punctal end and extended onto the proximal cut end if the canaliculi into the lacrimal sac. Needle within the injection port is used for a good grip and for guiding and advancing the whole length into the sac area and needle is withdrawn, excess of tube length is cut short leaving about $1-1.5 \mathrm{~mm}$ at the punctal end exposed. A 6-0 suture is taken at the grey line to properly approximate the lid margins and appropriate 
suturing is done of the orbicularis oculi, skin and conjunctiva. A 6-0 vicryl suture is used to anchor the IV cannula on the conjunctival side and 6-0 silk suture is taken through the tube and anchored to the skin below the lid margin. The Cannula was left in situ for 12 weeks. Patient is followed up at 1 week, 2 week, 4 week and 6 week and 12 weeks post operatively. Complications of the procedure noted if any. Functional and anatomical success evaluated and noted. Absence of epiphora was considered as the success of the surgery. Data analysed using descriptive statistics.

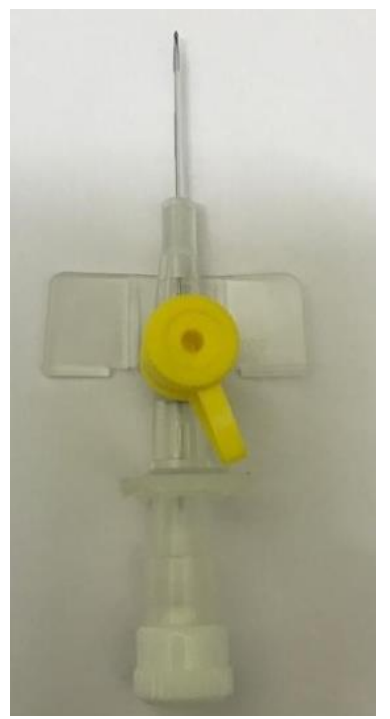

Fig. 1: 24G cannula

\section{Results}

In total of 32 patients included in our study, 24 were males and 8 females. (Table 1) Age distribution varied from 6 years to 58 years, with maximum number of patients in the age group of 15-30 years (Table 2).

Various causes of trauma included dog bite, RTA, assault, self-injuries, domestic violence, cooker blast in varying percentages (Table 3 ). On examination, Right eye was involved in 22 patients and left eye in 10 patients. (Table 4)

Out of 32 patients anatomical and functional success was seen $93.75 \%$ (30 patients). 2 patients had epiphora post operatively. Out of 32 patients, additional second surgery like ptosis surgery, ectropion and entropion correction was required in 4 patients. Complications in our study included premature extrusion, cheese wiring of tube, corneal abrasion, foreign body sensation, cosmetic compliant of white material at the punctum (tube). Out of 5 cases with premature extrusion, 2 patients had epiphora and remaining 3 patients had partially patent canaliculi without epiphora. (Table 5)

Table 1: Gender distribution

\begin{tabular}{|l|c|c|}
\hline \multicolumn{1}{|c|}{ Gender } & Number & Percentage \\
\hline Males & 24 & 75 \\
\hline Females & 8 & 25 \\
\hline
\end{tabular}

Table 2: Age distribution

\begin{tabular}{|l|c|c|}
\hline \multicolumn{1}{|c|}{ Age (years) } & Number & Percentage \\
\hline$<5$ & 5 & 15.63 \\
\hline $6-15$ & 6 & 18.75 \\
\hline $16-30$ & 11 & 34.37 \\
\hline $31-49$ & 5 & 15.63 \\
\hline$>50$ & 5 & 15.63 \\
\hline
\end{tabular}

Table 3: Mode of injury

\begin{tabular}{|l|c|c|}
\hline \multicolumn{1}{|c|}{ Mode } & Number & Percentage \\
\hline Dog bite & 1 & 0.03 \\
\hline RTA & 15 & 46.87 \\
\hline Assault & 9 & 28.12 \\
\hline Self injury & 5 & 15.62 \\
\hline Domestic violence & 1 & 0.03 \\
\hline Cooker blast & 1 & 0.03 \\
\hline
\end{tabular}

Table 4: Laterality

\begin{tabular}{|l|c|c|}
\hline \multicolumn{1}{|c|}{ Eye } & Number & Percentage \\
\hline Right & 22 & 68.75 \\
\hline Left & 10 & 31.25 \\
\hline
\end{tabular}

Table 5: Complications

\begin{tabular}{|l|c|c|}
\hline \multicolumn{1}{|c|}{ Complication } & Number & Percentage \\
\hline Premature extrusion & 5 & 15.62 \\
\hline Cheese wiring of tube & 1 & 0.03 \\
\hline Foreign body sensation & 2 & 0.06 \\
\hline Cosmetic compliant & 2 & 0.06 \\
\hline Corneal abrasions & 2 & 0.06 \\
\hline
\end{tabular}

\section{Discussion}

Canalicular tear are quite common secondary to various modes of injury. Various methods of tear repair have been tried in the literature such as mini monoka stent, bicanalicular repair, Crawford stent, Ritleng stents. Though all these stents have been shown to be successful, the more economical and easy modifications are required in the government set up. In our study we have come up with a novel and economical modification of canalicular tear repair by using easily available intravenous cannula of $24 \mathrm{G}$ size. In our study we found the male preponderance in the canalicular tear similar to the studies such as Jordan et al and Naik et al. 5,6

Various mode of injury included RTA, dog bite selfinjuries, assault. Most common cause in our study was RTA, which is similar to the studies conducted by Singh et $\mathrm{al}^{7}$ and $\mathrm{Wu}$ et al. ${ }^{8}$ Anatomical success and functional success in seen $93.75 \%$ (30 cases) by our modified technique This is much similar to the outcome seen in various studies such as Lee et al, ${ }^{9}$ Eo $\mathrm{S}$ et $\mathrm{al}^{10}$ in which they have used mini monoka stents. Other studies such as study done by Liang et $\mathrm{al}^{11}$ and Chowdhary et $\mathrm{al}^{12}$ who used bicanalicular stents and mini monoka stents also showed more than $90 \%$ of success in the outcome.

In our study, we have used $24 \mathrm{G}$ yellow colour cannula with the wings, that has $0.7 \mathrm{~mm}$ of diameter and $19 \mathrm{~mm}$ of length. Fig. 1) Advantages of our technique is that the 
intravenous cannula is readily available in the government set up and more economical. It does not cost extra to the patients. Also the cannulas have better gripping and easy to insert due to wings, also the insertion of the cannula through the canaliculi is made easy by the guiding of the needle within the cannula.

Various complications are seen in our procedure also, such as tube extrusion, cheese wiring of tube, foreign body sensation, corneal abrasion. Out of 5 cases with premature extrusion, 2 patients had epiphora and remaining 3 patients had partially patent canaliculi without epiphora. Absence of epiphora was considered as the success of the surgery in our study. In 4 of our cases, they required additional procedures for the associated lid conditions such as ptosis repair, entropion and ectropion correction. Ptosis occurs due to the damage to the levator muscle and its aponeurosis in cases of upper lid canalicular tear. Stent extrusion is the most common complication in most of the canalicular tear repairs in our study. In studies done by Singh et al $28 \%$ of stent extrusion was seen. ${ }^{7}$

\section{Conclusion}

Though there are many methods to correct canalicular tears using various stents, our modification of using stents which is intravenous cannula is found to be more economical, easily available with better anatomical and functional outcome.

\section{Conflict of Interest: Nil.}

\section{References}

1. Herzum H, Holle P, Hintschich C. Eyelid injuries: Epidemiological aspects. Ophthalmol. 2001;98:1079-1082.

2. Chu YC, Ma L, Wu SY, Tsai YJ. Comparing pericanalicular sutures with direct canalicular wall sutures for canalicular laceration. Ophthal Plast Reconstr Surg. 2011;27:422-425.

3. Kersten RC, Kulwin DR. "One-stitch" canalicular repair. A simplified approach for repair of canalicular laceration. Ophthalmol. 1996;103:785-789.

4. Tint NL, Alexander P, Cook AE, Leatherbarrow B. Eyelid avulsion repair with bi-canalicular silicone stenting without medial canthal tendon reconstruction. Br J Ophthalmol. 2011;95:1389-1392.

5. Jordan DR, Gilberg S, Mawn LA. The round-tipped, eyed pigtail probe for canalicular intubation: A review of 228 patients. Ophthal Plast Reconstr Surg. 2008;24:176-180.

6. Naik MN, Kelapure A, Rath S, Honavar SG. Management of canalicular lacerations: Epidemiological aspects and experience with Mini-Monoka monocanalicular stent. Am J Ophthalmol. 2008;145:375-380.

7. Singh M, Gautam N, Ahir N, Kaur M. Is the distance from punctum a factor in the anatomical and functional success of canalicular laceration repairs?. Indian J Ophthalmol. 2017;65:1114-1119.

8. Wu SY, Ma L, Chen RJ, Tsai YJ, Chu YC. Analysis of bicanalicular nasal intubation in the repair of canalicular lacerations. Jpn J Ophthalmol. 2010;54:24-31.

9. Lee H, Chi M, Park M, Baek S. Effectiveness of canalicular laceration repair using monocanalicular intubation with Monoka tubes. Acta Ophthalmol. 2009;87:793-796.
10. Eo S, Park J, Cho S, Azari KK. Microsurgical reconstruction for canalicular laceration using Monostent and Mini-Monoka. Ann Plast Surg. 2010;64:421-427.

11. Liang X, Lin Y, Wang Z, Lin L, Zeng S, Liu Z, et al. A modified bicanalicular intubation procedure to repair canalicular lacerations using silicone tubes. Eye (Lond) 2012;26:1542-1547.

12. Chowdhury HR, Rose GE, Ezra DG. Long-term outcomes of monocanalicular repair of canalicular lacerations. Ophthalmol. 2014;121:1665-1666.

How to cite this article: Anuradha A, Kulkarni V. M, Vidya D. M, Ranjitha C. S.A study of modified and economical approach to canalicular tear using intravenous cannula in tertiary care centre. Int J Ocul Oncol Oculoplasty. 2018;4(4):169-171. 